\title{
Accounting for the effect of heterogeneous plastic deformation on the formability of aluminium and steel sheets
}

\author{
N. R. Small ${ }^{1}$ - D. K. Williams ${ }^{1} \cdot$ R. Roy ${ }^{1} \cdot$ S. K. Hazra ${ }^{1}$ (10 \\ Received: 7 January 2020 / Accepted: 28 April 2020 / Published online: 3 July 2020 \\ (C) The Author(s) 2020
}

\begin{abstract}
Forming limit curves characterise "mean" failure strains of sheet metals. Safety levels from the curves define the deterministic upper limit of the processing and part design window, which can be small for high strength, low formability materials. Effects of heterogeneity of plastic deformation, widely accepted to occur on the microscale, are neglected. Marciniak tests were carried out on aluminium alloys (AA6111-T4, NG5754-O), dual-phase steel (DP600) and mild steel (MS3). Digital image correlation was used to measure the effect of heterogeneity on failure. Heterogeneity, based on strain variance, was modelled with the 2component Gaussian mixture model, and a framework was proposed to (1) identify the onset of necking and to (2) re-define formability as a probability to failure. The results were "forming maps" in major-minor strain space of contours of constant probability (from probability, $P=0$ to $P=1$ ), which showed how failure risk increased with major strain. The contour bands indicated the unique degree of heterogeneity in each material. NG5754-O had the greatest width ( 0.07 strain) in plane strain and MS3 the lowest ( 0.03 strain). This novel characterisation will allow engineers to balance a desired forming window for a component design with the risk to failure of the material.
\end{abstract}

Keywords Digital image correlation $\cdot$ Gaussian models $\cdot$ Forming limit curves $\cdot$ Stamping process $\cdot$ Automotive manufacturing

\section{Introduction}

Forming limit curves (FLCs) characterise the failure of metallic sheet materials. They are frequently used for material selection and for the simulation of the sheet metal forming process. With the increasing adoption of high-strength materials with smaller forming windows, engineers are motivated to measure their FLCs as accurately as possible and to identify individual safety margins for their materials.

\section{S. K. Hazra}

sumit.hazra@warwick.ac.uk

N. R. Small

nsmall7@jaguarlandrover.com

D. K. Williams

david.k.williams@warwick.ac.uk

R. Roy

r.roy@warwick.ac.uk

1 Faculty of Science, WMG, University of Warwick, Gibbet Hill Road, Coventry CV4 7AL, UK
The concept of the forming limits along varying strain paths was introduced by SP Keeler and G Goodwin in 1968 [1]. The concept has since been standardised in ISO 120042:2008 [2] and characterises formability from the uniaxial to the balanced biaxial strain path. Initial versions of the concept characterised failure in terms of "no failure", "near failure" and "failure". However, the standard method characterises failure as the onset of necking. It assumes continuum behaviour and therefore averages out any heterogeneity resulting from plastic deformation. It covers three aspects of the test: the method to deform the material, the technique for measuring deformation of the material and the method for determining the limit strains at the localised neck. The material can be deformed by following either the Nakajima or Marciniak method. Deformation of the material may be measured either by etching a grid on the sample surface or more commonly, with state-of-the-art digital image correlation (DIC). With DIC, the deformation of the sample is measured for the duration of the test with a set of optical cameras. The forming limits of the material are then identified with a "position-dependent" analysis of the strains just before the crack becomes visible. Practically, identifying the onset of cracking is subjective as it is a gradual process. DIC measurements show 
deformation to be "noisy" for most materials, making the onset of failure ambiguous to determine. The formability of a sheet material may also be characterised with other tests. Some, such as the limiting-dome height test and the Swift cupping test, are simulative tests which are appropriate for empirical measurements. Others, such as the bulge test, characterise material properties for a limited number of strain paths [1].

Amongst efforts to improve the accuracy of forming limits, one route is to reduce subjectivity by using "time-dependent" analysis, where the chronology of deformation measured by DIC of an FLC test is used to determine the onset of necking. Figure 1 shows a schematic of a material deformation parameter, such as major strain, that is tracked until failure. The onset of necking is associated with the inflection of the monotonically increasing curve. Three aspects to time-dependent methods have to be established:

1. The material deformation parameter to be tracked, such as major strain is identified.

2. The area on the sample surface to be tracked. This can range from a circular area to a single point on the sample surface. The areas chosen should cover the region of the sample that eventually necks.

3. The method used to identify the onset of necking. Two methods are used: the "broken-stick" regression method or simply defining a threshold, such as the acceleration of major strain.

When the broken-stick regression is used, a pair of linear curves is fitted to the data on either side of the inflection of the material deformation parameter (Fig. 1). The intersection of the linear curves marks the time or the frame at which necking occurs.

Table 1 summarises six time-dependent approaches that have been developed recently. Merklein et al. [3] monitored

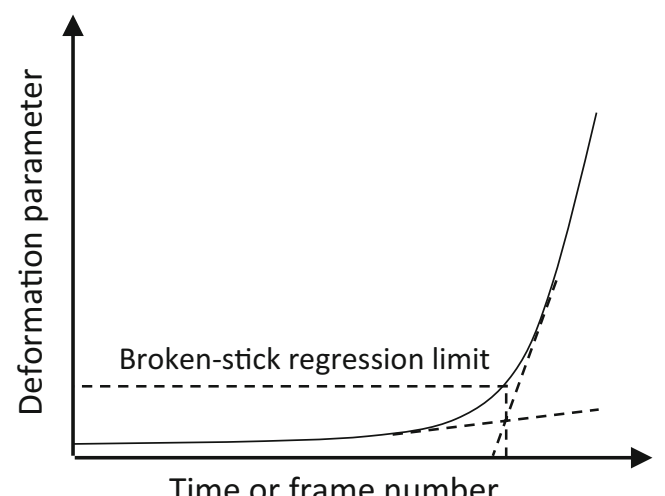

Fig. 1 Schematic of a material deformation parameter that evolves in time and undergoes necking. The figure illustrates how a broken-stick regression is used major strain rate in a circular area to failure in a HX260 steel and an AA6016 aluminium. They associated the onset of necking with the occurrence of a maximum in the major strain rate and the derivative of major strain rate respectively. Their technique produced a similar FLC for HX260 steel compared with the ISO method but a higher FLC for AA6016, particularly in the right-hand side.

Volk and Hora [4] monitored thinning acceleration along a line perpendicular to the eventual cracks in their samples of HC220YD steel at $0.8 \mathrm{~mm}, 1.1 \mathrm{~mm}$ and $1.6 \mathrm{~mm}$. The onset of necking was identified with broken-stick regressions of the thinning acceleration. They did not compare their results against the ISO method but found agreement between experiments carried out between two laboratories.

Hotz et al. [5] monitored thinning rate in a circular area measuring $2 \mathrm{~mm}$ across but did not specify the material they tested their materials on. They proposed a broken-stick regression to identify the onset of necking. Min et al. [6] carried out plane strain Marciniak tests on 1.2-mm MP980 steel, 1.0-mm DP600 steel and 1.0-mm AA6022-T4 aluminium and compared Hotz et al. 2013's method with the ISO method. They found that the DP600 and MP980 forming limits were measured to be higher using Hotz et al.'s [5] method compared with the ISO method while the AA6022 was lower.

Huang et al. [7] monitored the second derivative of major strain but track just a single point in the neck. They identified the onset of necking on the increase of strain. When Min et al. [6] compared Huang et al.'s [7] method with the ISO method, they found that the forming limits of DP600 and MP980 were measured to be higher, while AA6022 was measured to be lower.

Vysochinskiy et al. [8] monitored the ratio of the thickness in the neck and its surrounding area, $k$, in 2 circular areas of their samples: an inner circle and an outer circle. The inner circle contained the neck while the area between the inner and outer circle containing un-necked material. The onset of necking was detected with a threshold value, $k_{\text {limit }}$. When compared with the ISO method, the method measured similar forming limits on the right-hand side for an AA6016 aluminium.

Martinez-Donnaire et al. [9] monitored major strain and tracked the strains along a line across the eventual crack. Failure was detected at the threshold of maximum strain rate. In their plain strain Marciniak tests, Min et al. [6] applied the Martinez-Donnaire et al.'s [9] technique and found that, when compared with the ISO method, the technique measured forming limits that were similar for DP600 and MP980 but was lower for AA6022.

To summarise, compared with the ISO method, timedependent methods produced FLCs that were similar or higher for steels. For aluminiums, there was no clear trend. The level of a time-dependent FLC was higher or lower to the ISO method, depending on the technique used. As a result, 
Table 1 Summary of literature on time-dependent methods

\begin{tabular}{|c|c|c|c|c|c|}
\hline Paper & Deformation parameter & $\begin{array}{l}\text { No. of points } \\
\text { tracked }\end{array}$ & Onset of necking & Materials & Comments \\
\hline Merklein et al. [3] & Major strain rate & $\begin{array}{l}\text { Circular area } \\
\text { covering crack }\end{array}$ & $\begin{array}{l}\text { Maximum of } \\
\text { derivative of } \\
\text { major strain rate }\end{array}$ & $\begin{array}{l}\text { - HX260 micro } \\
\text { alloyed steel } \\
\text { - AA6016 }\end{array}$ & $\begin{array}{l}\text { Authors compared with ISO: } \\
\text { • HX260 was similar } \\
\text { - AA6016 FLC was higher on RH, }\end{array}$ \\
\hline Volk and Hora [4] & Thinning acceleration & Line across crack & $\begin{array}{r}\text { Broken-stick } \\
\text { regression }\end{array}$ & $\begin{array}{l}\text { HC220YD steel, } 0.8 \\
\text { mm, } 1.1 \mathrm{~mm} \text { and } \\
1.6 \mathrm{~mm}\end{array}$ & $\begin{array}{l}\text { - Comparison was between } 2 \text { labs. } \\
\text { Similar results obtained }\end{array}$ \\
\hline Hotz et al. [5] & Thinning rate & $\begin{array}{l}\text { Circular area } \\
\qquad(1 \mathrm{~mm} \text { radius })\end{array}$ & $\begin{array}{r}\text { Broken-stick } \\
\text { regression }\end{array}$ & Not known & $\begin{array}{l}\text { - Follows Volk and Hora, } 2010 \\
\text { technique } \\
\text { - Min et.al., } 2017 \text { compared with ISO: } \\
\text { DP600: higher, MP980: higher, } \\
\text { AA6022: lower }\end{array}$ \\
\hline Huang et al. [7] & $\begin{array}{l}\text { Second derivative of } \\
\text { major strain }\end{array}$ & $\begin{array}{l}\text { A single point in } \\
\text { the neck }\end{array}$ & $\begin{array}{l}\text { At the onset of } \\
\text { strain increase }\end{array}$ & & $\begin{array}{l}\text { - Min et.al., } 2017 \text { compared with ISO: } \\
\text { DP600: higher, MP980: higher, } \\
\text { AA6022: lower }\end{array}$ \\
\hline $\begin{array}{l}\text { Vysochinskiy et al. } \\
\text { [8] }\end{array}$ & $\begin{array}{c}k=\text { thickness in the } \\
\text { neck/thickness in } \\
\text { surrounding area }\end{array}$ & $\begin{array}{l}1 \text { outer and } 1 \text { inner } \\
\text { circle. Radius } \\
\text { was varied }\end{array}$ & $\begin{array}{l}\text { Set a limit } \\
\quad \text { definition, } k_{\text {limit }}\end{array}$ & AA6016 & $\begin{array}{l}\text { - Authors compared with ISO, lower } \\
\text { FLC on RHS }\end{array}$ \\
\hline $\begin{array}{l}\text { Martinez-Donnaire } \\
\text { et al. [9] }\end{array}$ & Major strain & Line across crack & $\begin{array}{l}\text { Maximum of } \\
\text { major strain rate }\end{array}$ & AA7075-O & $\begin{array}{l}\text { - Min et.al., } 2017 \text { compared with ISO: } \\
\text { DP600: similar, MP980: similar, } \\
\text { AA6022: lower }\end{array}$ \\
\hline
\end{tabular}

defining the onset of necking more accurately with deformation parameters such as major strain rate has been mixed.

\subsection{Formability as a risk to failure}

FLCs determined with the ISO or time-dependent methods separate the regions of failure and safety in a binary or deterministic manner because they assume that plastic deformation occurs smoothly and homogeneously until failure. Fluctuations in a DIC measurement are treated as noise to be neglected. For example, Merklein et al. [3] state that "...to reduce scatter of the strain values it is recommended to calculate the mean value of major strains...".

However, it is well accepted that at the microscale, plastic deformation occurs through the slip of crystallographic planes and rotation of grains. The result is a heterogeneous strain field that has statistical characteristics. Boas and Hargreaves [10] first highlighted this in a single-phase aluminium by measuring the elongation in grains of AA1 $\mathrm{xxx}$ aluminium after $5 \%$ uniaxial deformation. They found variation of strain both within grains and across grain boundaries. At longer length scales, Hazra et al. [11] uniaxially deformed polished DP1000 steels using a Deben MT5000 in situ mechanical testing stage that was installed in a scanning electron microscope. Its microstructures were imaged periodically as the sample was mechanically deformed. The evolving pattern of the microstructure was tracked with the LaVision DIC software to calculate its full-field strain distribution [11]. The results are images of full-field strain distribution that reflects the phase distribution of the material (Fig. 2). In particular, they found that deformation concentrated in the softer, ferrite phase.

This heterogeneity at the microscale is assumed to homogenise at the macroscale but in reality, this is not always so. For example, under applied load, surface grains are free to rotate and will deform preferentially according to their orientation to the load. If the material is stretched sufficiently, the collective deformation of similarly textured grains causes an undulating surface, which can have the appearance of "orange peel". Tadros and Mellor [12] carried out Marciniak-Kuczynski analyses on steel, aluminium and brass and predicted that this type of heterogeneity can be severe enough to affect

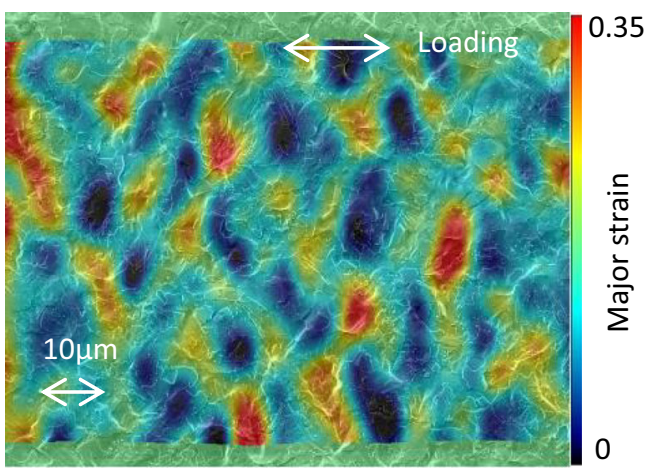

Fig. 2 The deformation of a DP1000 microstructure was imaged in a scanning electron microscope and analysed with digital image correlation. The contour plot shows that, at UTS, the major strain in the microstructure varied from 0 to 0.35 true strain 
formability. Although, they did not make probabilistic assessments, they predicted that a $1.2 \%$ variation in thickness can alter formability by $23 \%$, suggesting that variability from "orange peel" will affect forming limits.

The variability of forming limits can also be observed at the macroscale when a sufficiently large sample is measured. Van Minh et al. [13] and Janssens et al. [14] measured the forming limits of around 500 and 60 mild steel specimens respectively, and each measurement was treated deterministically with a method similar to the current ISO methodology. When they analysed the resulting scatter in the forming limits of their large sample sizes, they concluded that over a large number of samples, forming limits is probabilistic and that the standard deviation of the forming limits was greater than can be explained by experimental error.

\section{Approach}

In this work, we drop the continuum assumption to investigate the effect of heterogeneity in plastic deformation on formability. This was carried out by including the statistical characteristics of deformation that are captured by DIC measurements. Figure $3 \mathrm{~b}$ shows the DIC measurements of a Marciniak test (Fig. 3a) at the onset of necking. The topology of thickness strains, $\varepsilon_{3}$, shows the complexity of the strain distribution that is typically present at the onset of necking. The fluctuations imply that material is deformed to different extents in different areas, resulting in a heterogeneous strain distribution.

It was demonstrated, through a design of experiment, that these fluctuations were significant compared with the uncertainty of the DIC measuring system in terms of its accuracy and precision ("Establishing the measurement uncertainty of DIC" section). A series of Marciniak tests were then carried out on 2 aluminium grades, NG5754-O, AA6111-T4, a mild steel grade, MS3 and a dual-phase steel, DP600. The observed heterogeneity was modelled with Gaussian models to quantify the mean and dispersion of the distributions. Single distributions were observed during the uniform deformation phase. At the onset of necking, the single distribution became "multimodal" or formed multiple distributions ("The strain distribution during plastic deformation" section). The Gaussian models were used to develop a framework to characterise formability as a probability to failure ("Characterising the formability of a material" section). The novelty of this work is the observation (1) that the DIC system is able to detect heterogeneity of plastic deformation at the macroscale, (2) that the presence of heterogeneity means that the forming limits of each measurement is uncertain and can only be stated probabilistically and (3) that the range over which failure can occur can be used as a basis to balance the desired forming window with the risk of failure.

\section{Establishing the measurement uncertainty of DIC}

The DIC system used in this work was a GOM Aramis DIC system that consisted of a pair of Vosskuhler 1300bg cameras, fitted with 50-mm lenses. The cameras had monochrome sensors with a resolution of $1280 \times 1024$ pixels. A monochromatic speckle pattern was applied to the gauge are of each sample.

Measurement uncertainty was determined under three conditions using the Nakajima test setup (Fig. 4): depth of the punch, blankholder force and orientation of the blank.

Depth of the punch (Fig. 4b) was identified as a factor because as the sample deforms, the sample is located in

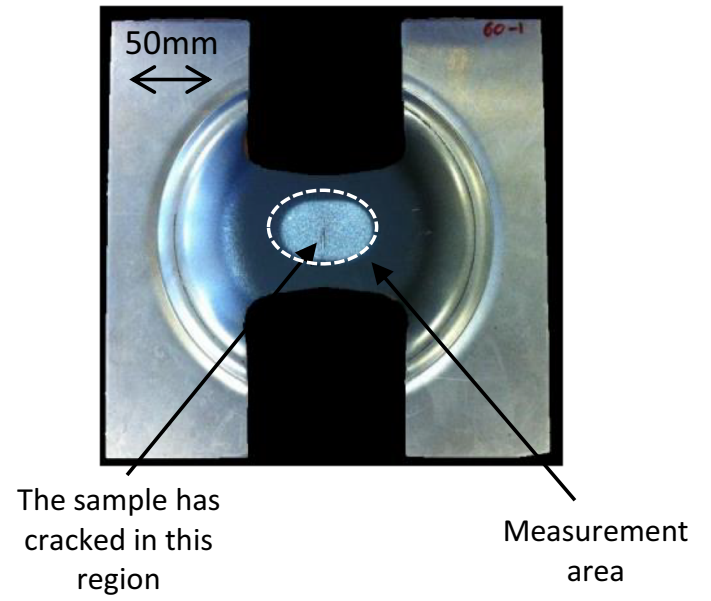

(a)

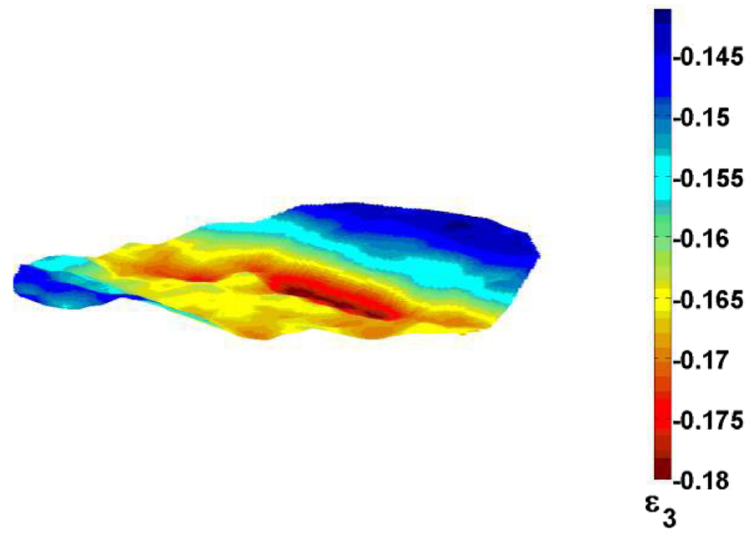

(b)

Fig. 3 a Failed Marciniak sample and the central region $(\varnothing 30 \mathrm{~mm})$ where DIC measurements were carried out. b True thickness strain, $\varepsilon_{3}$ at the onset of necking 
Fig. 4 a Experimental setup for the FLC tests. "A" is the Erichsen 145-50 sheet metal forming tester, " $\mathrm{B}$ " is the DIC cameras and " $\mathrm{C}$ " is the DIC controller and data acquisition system. b Cross section of Nakajima tooling

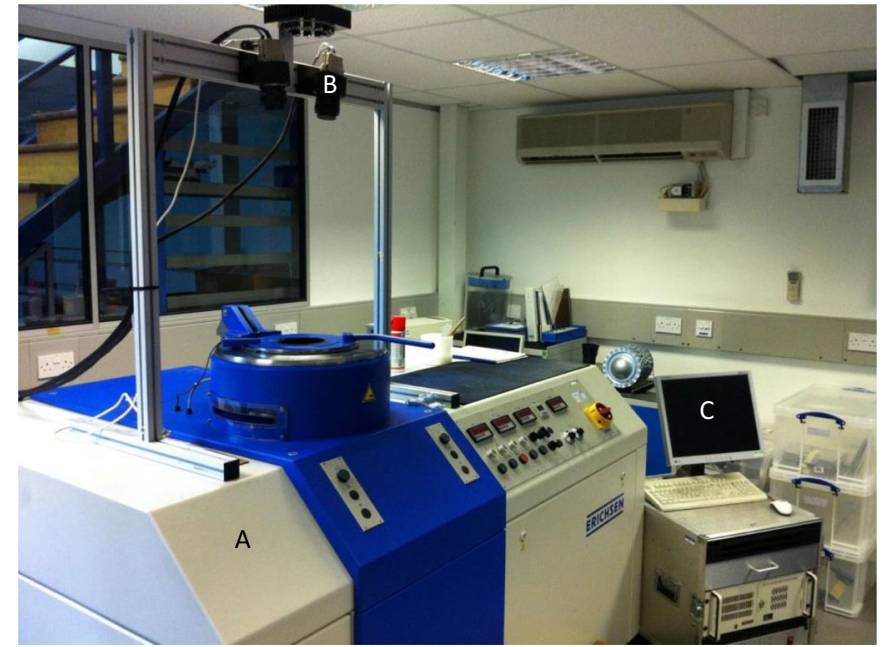

(a)

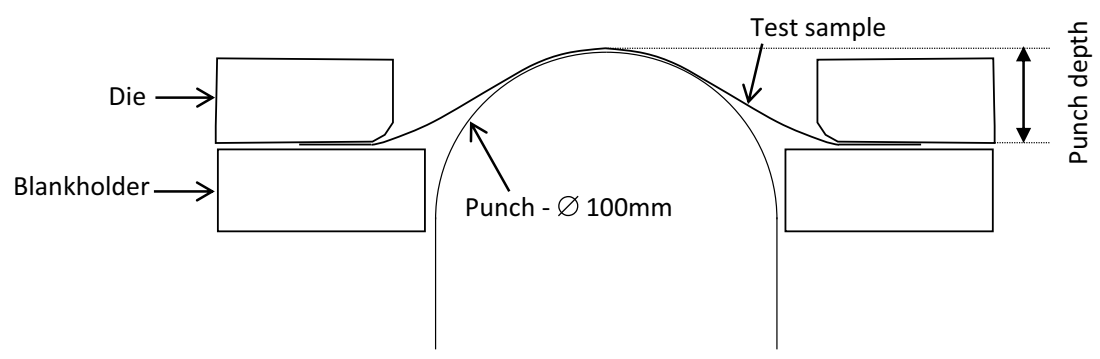

(b) different areas of the measurement volume and the angle required to view all areas of the sample changes can cause errors in tracking the pattern. Blankholder force was a second factor because the camera system was mounted on an Erichsen 14560 sheet forming test machine that used hydraulic actuators to operate the blankholder. As the camera structure was mounted on the casing of the machine, vibrations from the machine as it applied blankholder pressure on the sheet could have been transmitted to the cameras, causing blurring of the images and errors in tracking the pattern on the samples. Finally, the sample was rotated on the blankholder by $0^{\circ}, 90^{\circ}, 180^{\circ}$ and $270^{\circ}$ without application of load. This was done to determine the effect of the applied pattern on measurement uncertainty because Hild and Roux [15], in a review of DIC accuracy, identified this as an important factor. To test for the effect of these factors, a full factorial experiment was carried out. Table 2 lists the factors and the conditions of the test.

For tests where punch depth was 10, 20 and $30 \mathrm{~mm}$, the speckle pattern was applied to each sample after it was deformed. This was done to measure the accuracy of a known strain value, zero strain, at the various punch heights. Assuming that the zero-strain measurements are normally distributed, the means of the measurements were used to describe the accuracy of the measurements (within a given tolerance, or standard error) and its standard deviation to describe precision.

The material tested was $1.2-\mathrm{mm}$ thick DX54, a mild steel grade. Each sample was cut into a $220-\mathrm{mm}$ sided square. The speckle pattern applied to the samples consisted of a matt black background followed by a white speckle pattern (50:50 mixture of white emulsion paint to water) using an airbrush held at a distance of approximately $0.3 \mathrm{~m}$ away from the sample. The camera system was calibrated and the camera angle was found to be $14.7^{\circ}$, the measurement volume was $115 \times 90 \times 70 \mathrm{~mm}$, measuring distance was $800 \mathrm{~mm}$ and the calibration deviation was 0.015 pixels. Each measurement contained about 3700 facets measuring $1 \mathrm{~mm}^{2}$ each.

Table 2 Conditions and levels under which measurement uncertainty was determined

\begin{tabular}{ll}
\hline Conditions & Levels \\
\hline Punch depth & Flat, $10 \mathrm{~mm}, 20 \mathrm{~mm}$ and $30 \mathrm{~mm}$ \\
Blankholder force & $0 \mathrm{kN}, 300 \mathrm{kN}$ and $600 \mathrm{kN}$ \\
Blank orientation & $0^{\circ}, 90^{\circ}, 180^{\circ}$ and $270^{\circ}$ \\
\hline
\end{tabular}


The mean major strain, $\varepsilon_{1}$, from the 48 experiments (Appendix Table 3) was less than 0.0005 and standard deviation was 0.0006 . The standard deviation was at least an order of magnitude lower than the plastic strains measured in the rest of this work. An analysis of variance found that depth had the greatest effect on measured strains and this was due to the increased dispersion from curvature. Blank holder force, sample orientation or factor interactions did not show a significant effect on the accuracy of the measured strains and will be considered negligible in this work.

\section{The strain distribution during plastic deformation}

The forming limit curve tests were carried out in accordance with the test procedure described in ISO12004-2 [1]. Marciniak tooling (Fig. 5) was chosen to minimise bending in the gauge area of the samples and to reduce measurement errors due to curvature of tooling described in the "Establishing the measurement uncertainty of DIC" section. Specimen geometries with 5 different widths in the gauge area were machined to test forming limits between the uniaxial and equibiaxial strain paths $(60 \mathrm{~mm}$, $100 \mathrm{~mm}, 120 \mathrm{~mm}, 160 \mathrm{~mm}$ and $220 \mathrm{~mm}$, Fig. 5). Three repeats were carried out. Carrier blanks for the Marciniak test were manufactured from ductile DX-54 mild steel and mirrored the specimen geometries with the inclusion of a central 33-mm diameter hole. As before, the samples were tested on an Erichsen 145-60 machine and monochromatic speckle patterns were applied to the gauge are of each sample and its deformation was tracked with the GOM Aramis DIC system. Two aluminium grades, NG5754-O (1.5 mm), AA6111-T4 (1.2 mm), a mild steel grade, MS3 $(0.9 \mathrm{~mm})$ and a dual-phase steel, DP600 $(1.6 \mathrm{~mm})$ were tested.

\subsection{Exploratory data analysis}

To quantify the strain heterogeneity within the Marciniak samples, boxplots of thickness strains, $\varepsilon_{3}$, were calculated from the DIC strain data on AA6111-T4.

These typically showed that with increasing deformation, median $\varepsilon_{3}$ decreased non-linearly and dispersion increased (Fig. 6). The boxplots show the median lines to be central (indicating a symmetrical distribution) until the onset of necking. This showed that the strain distribution is approximately Gaussian until failure.

To understand the skew towards the end of the tests, the data was re-presented as a probability density function (PDF) using the kernel density estimation technique. The PDFs showed that at the start of the test, single-mode strain PDFs were apparent (Fig. 7). As the tests proceeded, the dispersion in the strains increased, as reflected in the increasing heights of the boxplots (Fig. 6). At the onset of failure when uniform deformation transitioned to localised deformation, the single mode transitioned into a bimodal distribution causing the skew in the boxplots.

\subsection{Modelling the heterogeneity of plastic deformation}

The statistical characteristics of the measured strains and their transitioning behaviour were modelled as a distribution-based clustering technique, the Gaussian mixture model (GMM). In particular, the 2-component GMM was used to describe the distributions as a superposition of two normal distributions, $g_{1}\left(\varepsilon_{3}\right)$ and $g_{2}\left(\varepsilon_{3}\right)$ :

$$
\begin{aligned}
f\left(\varepsilon_{3}\right)=g_{1}\left(\varepsilon_{3}\right)+g_{2}\left(\varepsilon_{3}\right)= & \pi_{1} N\left(\mu_{1}, \sigma_{1}\right) \\
& +\left(1-\pi_{1}\right) N\left(\mu_{2}, \sigma_{2}\right)
\end{aligned}
$$

where $\varepsilon_{3}$ is the thickness strain, $\pi_{1}$ and $\left(1-\pi_{1}\right)$ are the mixing proportions of the two distribution and $N\left(\mu_{l}, \sigma_{l}\right)$ and
Fig. 5 Cross section of Marciniak test tooling, test sample and spacer arrangement

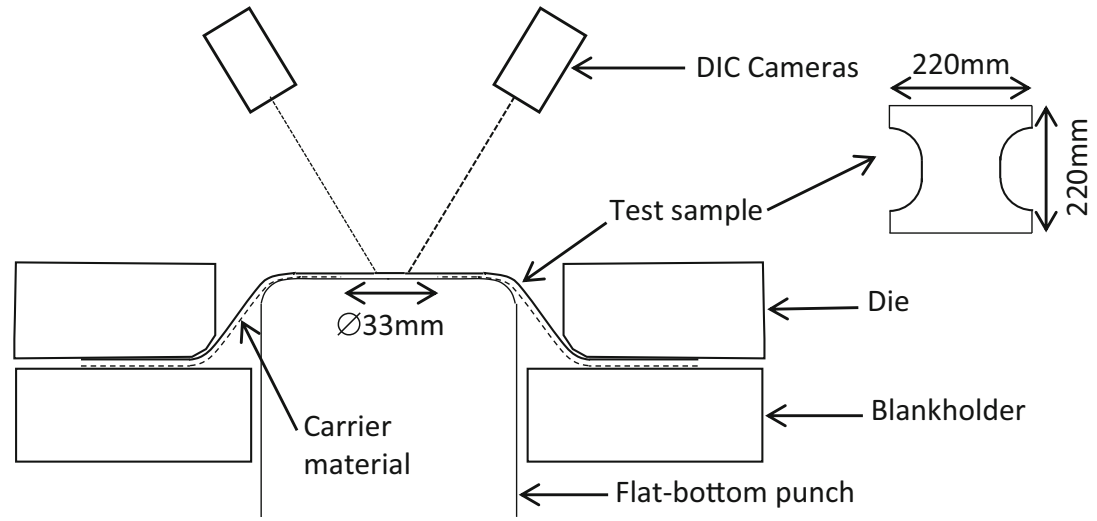


Fig. 6 Boxplot of $\varepsilon_{3}$ measured during a Marciniak test of AA6111T4 in plane strain. Height of the box represents the 25th to 75 th percentile range, the middle line shows the median and whiskers show the extreme measurements

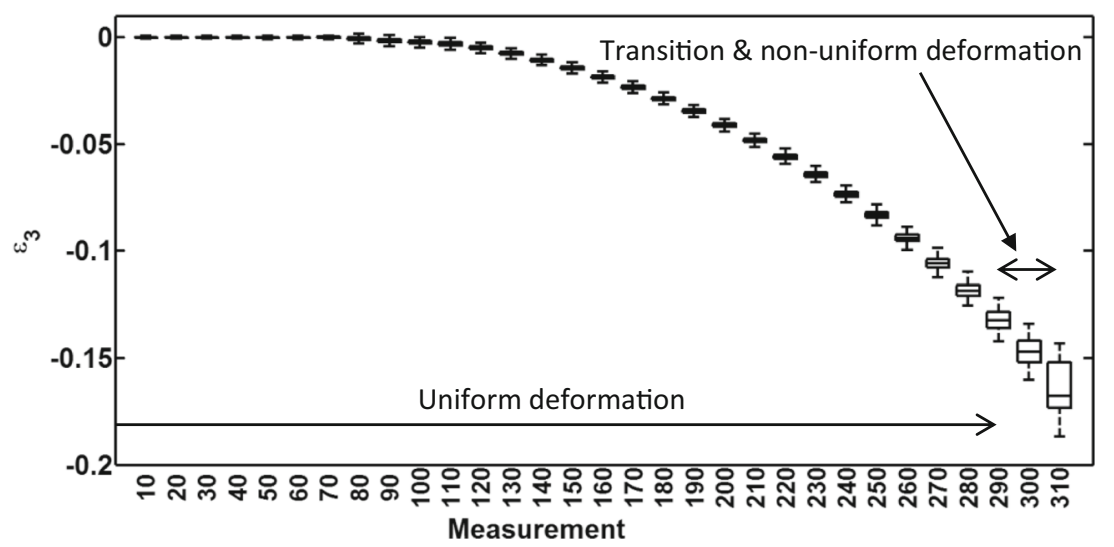

$N\left(\mu_{2}, \sigma_{2}\right)$ are the Gaussian functions of each component:

$N(\mu, \sigma)=\frac{1}{\sigma \sqrt{2 \pi}} e^{\frac{-\left(\varepsilon_{3}-\mu\right)^{2}}{2 \sigma^{2}}}$

where $\mu$ is the mean of a distribution and $\sigma$ is its standard deviation. The mixing proportions of the components were determined by calculating the relative probability density of each component at each measured data point. Say, two components are observed during necking (Fig. 8).

Measured data point $\mathrm{A}^{*}$ can belong to either components (in all tests, the components were not mutually exclusive, and they overlapped). The probability that $\mathrm{A}^{*}$ belongs to each component is calculated from the relative probability density of each component at point $\mathrm{A}^{*}$.

$P\left(g_{1}\left(\varepsilon_{3}\right) \mid A^{*}\right)=\left.\frac{g_{1}\left(\varepsilon_{3}\right)}{g_{1}\left(\varepsilon_{3}\right)+g_{2}\left(\varepsilon_{3}\right)}\right|_{A^{*}}$

$P\left(g_{2}\left(\varepsilon_{3}\right) \mid A^{*}\right)=\left.\frac{g_{2}\left(\varepsilon_{3}\right)}{g_{1}\left(\varepsilon_{3}\right)+g_{2}\left(\varepsilon_{3}\right)}\right|_{A^{*}}$

$\mathrm{A}^{*}$ would be classified as belonging to component 2 if $P\left(g_{2}\left(\varepsilon_{3}\right) \mid x\right)>0.5$ or to component 1 if $P\left(g_{1}\left(\varepsilon_{3}\right) \mid x\right)<0.5$. The GMM was constructed using the expectation maximisation algorithm [9], which optimised the parameters of the GMM to fit the measured data. An example of a GMM model of an AA6111-T4 sample is given in Eq. 5. The model represents the PDF of the sample at the point of necking (Fig. 9). Comparing the GMM model with the kernel density estimation of the data shows its goodness-to-fit with the data. The PDF characterises the strain distribution measured at the point of necking (Fig. 10a). The values represent the parameters in Eq. 1

$$
\begin{aligned}
f\left(\varepsilon_{3}\right)= & 0.35 N(-0.149,0.0034) \\
& +0.65 N(-0.171,0.0058)
\end{aligned}
$$

Figure 10 shows that component 1 strains were from outside the neck and component 2 strains were from within the neck (Fig. 10). This behaviour was observed in all materials and tests.

\section{Characterising the formability of a material}

The observation that necking causes the GMM components to diverge was used as a characteristic material parameter for a time-dependent method to identify the onset of necking. In
Fig. 7 The evolution of probability distribution functions (PDFs) of thickness strains, $\varepsilon_{3}$, during a typical Marciniak test. The sample was deformed in plane strain. The strain evolution of the sample can be viewed as a video [16]

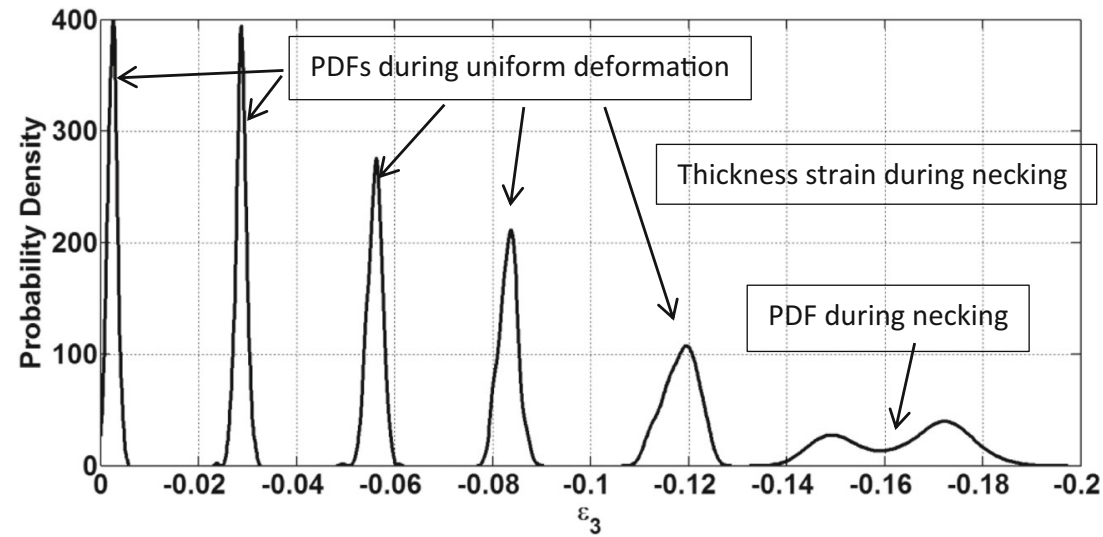




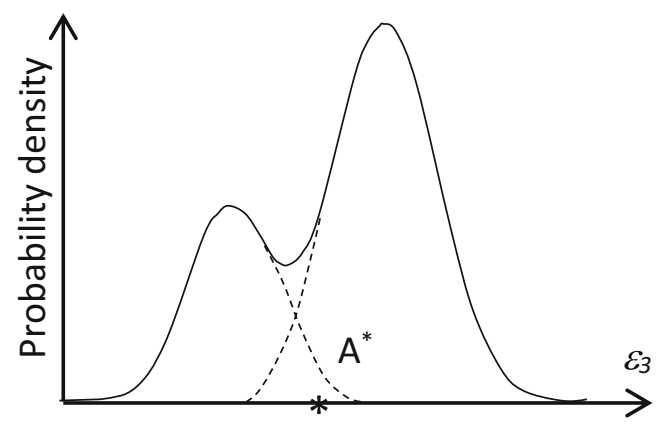

Fig. 8 The two components of the GMM at the outset of necking

particular, the difference in the means of the components of the GMM was tracked, and the onset of necking was identified with the broken-stick regression method. However, the presence of a spread of strains in the sample meant that it was not possible to associate the necking event with a single value of strain. Instead, the strains in the sample were evaluated for the probability that it belonged to the necked component.

The method was implemented in a Matlab 2012a program to automate the process. To identify the onset of necking:

1. The strains captured by the DIC instrument were modelled as the two-component GMMs (following Eq. 1).

2. The difference in means, $\left|\mu_{2}-\mu_{1}\right|$, between the two components for $\varepsilon_{3}$ was evaluated (Fig. 11).

3. $\left|\mu_{2}-\mu_{1}\right|$ was plotted with respect to the DIC measurement series (Fig. 12). The broken-stick regression identified the onset of necking.

Since a dispersion of strains always exists in a material, the formability of the material is better described in terms of a risk to failure. At the onset of necking:
1. The major and minor strains at this measurement point were plotted on a forming limit diagram.

2. Posterior probability of each strain measurement belonging to component 2 (the necked component) was calculated from the GMM:

$P\left(g_{2}\left(\varepsilon_{3}\right) \mid x\right)=\left.\frac{g_{2}\left(\varepsilon_{3}\right)}{g_{1}\left(\varepsilon_{3}\right)+g_{2}\left(\varepsilon_{3}\right)}\right|_{A}>0.5$

The posterior probability that each strain point belonged to the necked component was overlaid on each strain point.

3. The logistic regression was used to fit the posterior probability of necking (following Strano and Colosimo [18]). The regression is a cumulative probability of necking strains, (component 2) so the higher the measured strain, the greater probability of the measurement lying in component 2. Through trial and error, this transition behaviour was modelled as follows:

$\ln \left(\frac{P_{2}}{1-P_{2}}\right)=a \varepsilon_{1}^{2}+b \varepsilon_{2}^{2}+c \varepsilon_{1}+d \varepsilon_{2}+e$

where $a, b, c$ and $d$ are the fitting parameters for the model, $P_{2}$ is the probability of component 2 and $e$ is the residual error of the fit for the model.

The resulting curves assign probabilities to the strains that were classified as necking strain to represent a map of the probable formability of the material (Fig. 13). These curves were compared with forming limits calculated with the ISO method [1].
Fig. 9 A GMM PDF, its components and a kernel density estimation. The data was measured from a plane strain test of AA6111-T4 undergoing necking

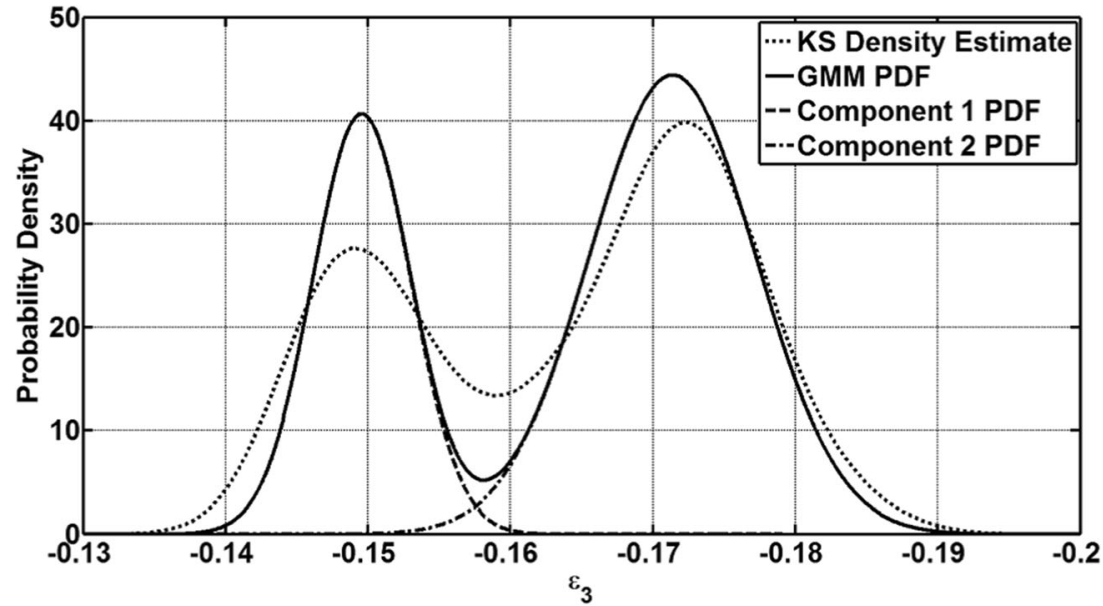


Fig. 10 Relationship between component 1 and 2 strains and the location they were measured on the sample in Fig. 8. a DIC measurement of sample. $\mathbf{b}$ The components of the GMM (raw data can be found in reference [17])

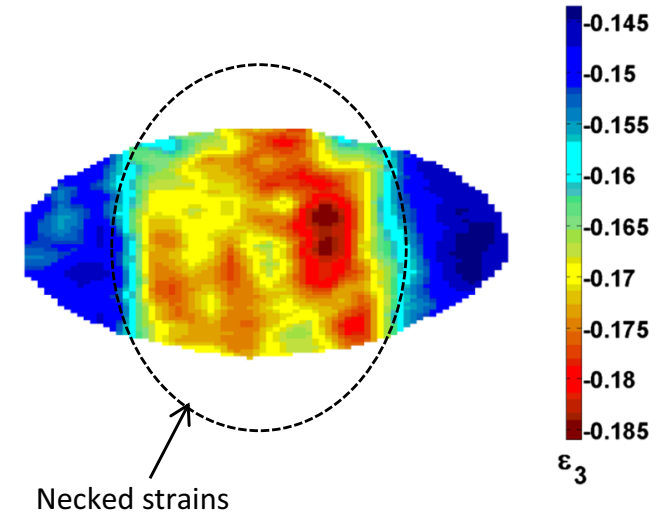

(a)

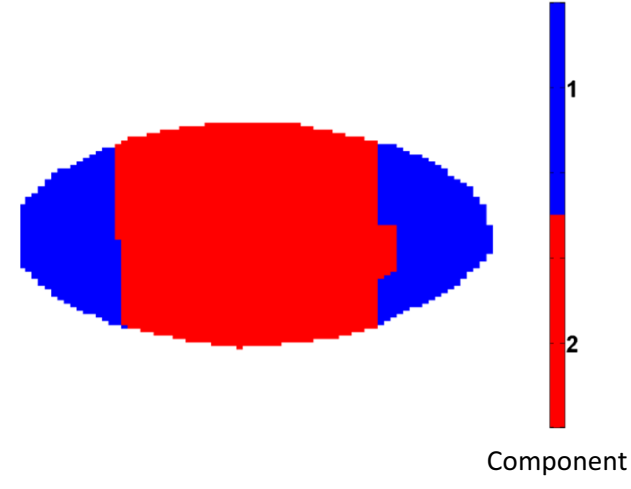

(b)

\section{Discussion}

When compared with ISO-based FLC data, the $\mathrm{P}($ failure $)=1$ contour was generally conservative or lower, apart from AA5754. This is due to the ability of the time-dependent procedure to identify the onset of necking by tracking the difference of the means between components 1 and $2,\left|\mu_{2}-\mu_{1}\right|$

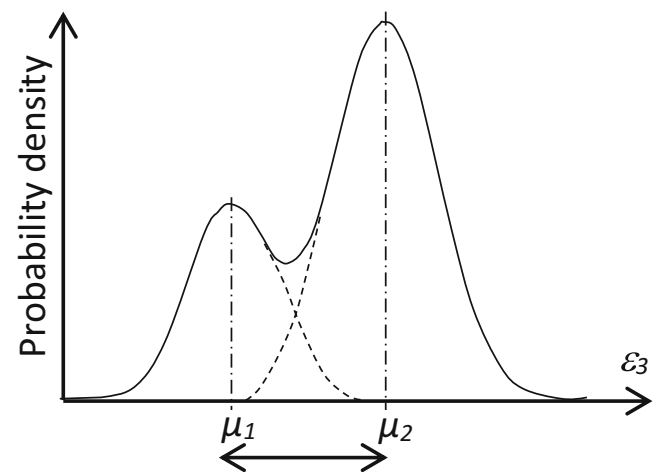

Fig. 11 Schematic indicating the difference between the mean $\varepsilon_{3}$ of the two components
(Fig. 12). The gap reflects the sensitivity of this method compared with the ISO method. The gap is particularly prominent for MS3 (Fig. 13d). Figure 14 shows that the rate of separation of the GMM components does not display as sharp an inflection as that exhibited by $1.2-\mathrm{mm}$ AA6111T4 (Fig. 12). This implies that the development of a localised neck is more gradual in MS3 than in AA6111T4. The large discrepancy between the probability map and the ISO-based FLC suggests that the inflection point in Fig. 14 is due to the onset of diffuse necking rather than localised necking, resulting in a lower forming limit.

The probabilistic forming limits may be compared more broadly with other time-dependent methods. Table 1 shows deformation parameters used by past authors for time-dependent methods to identify the onset of necking and calculate formability. For steels, these deformation parameters have measured forming limits to be either similar or higher than the ISO method. Since the ISO method relies on the visual identification of a crack to characterise the formability of a material, these deformation parameters either equal or overestimate the
Fig. 12 Plot of the mean difference in thickness strain against DIC measurement. The inflection indicates the occurrence of necking. Broken-stick regression identifies transition

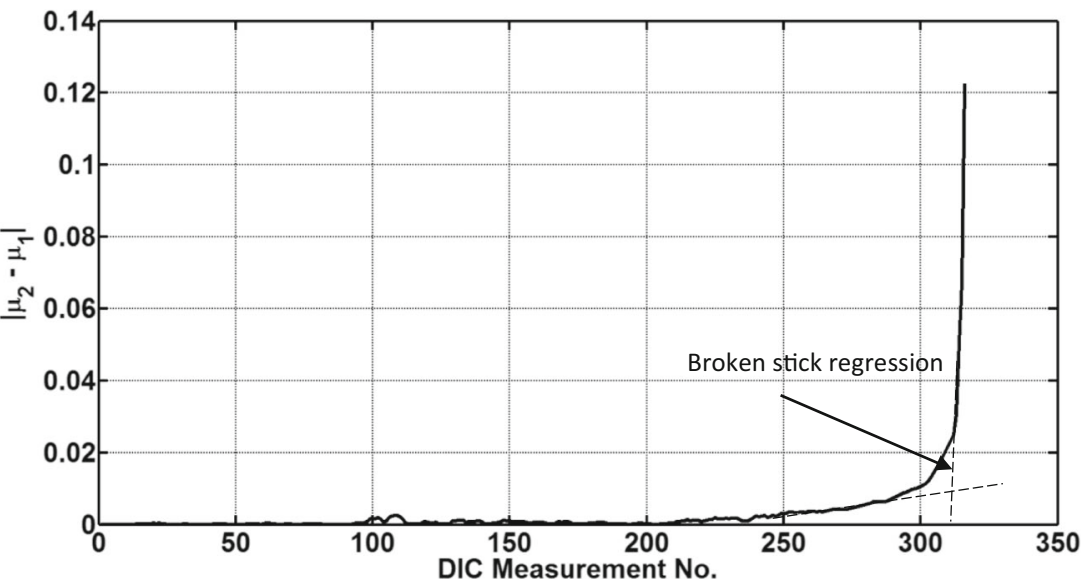




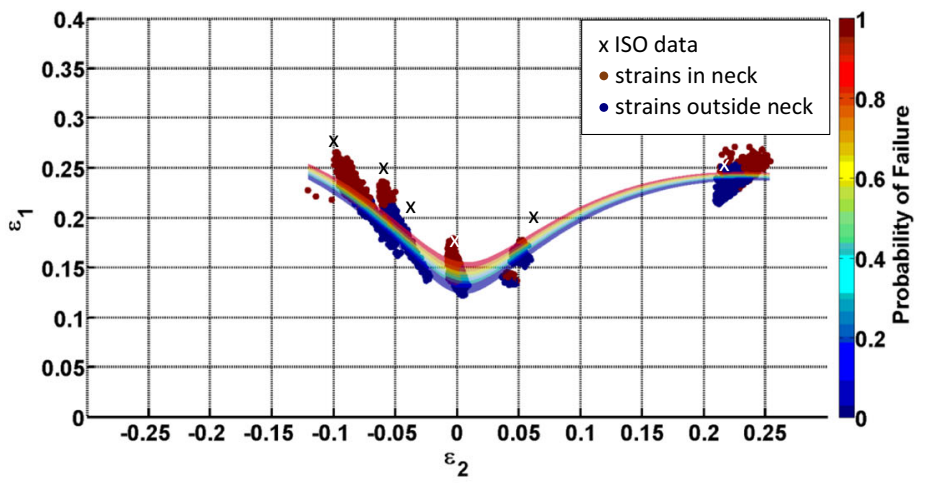

(a)

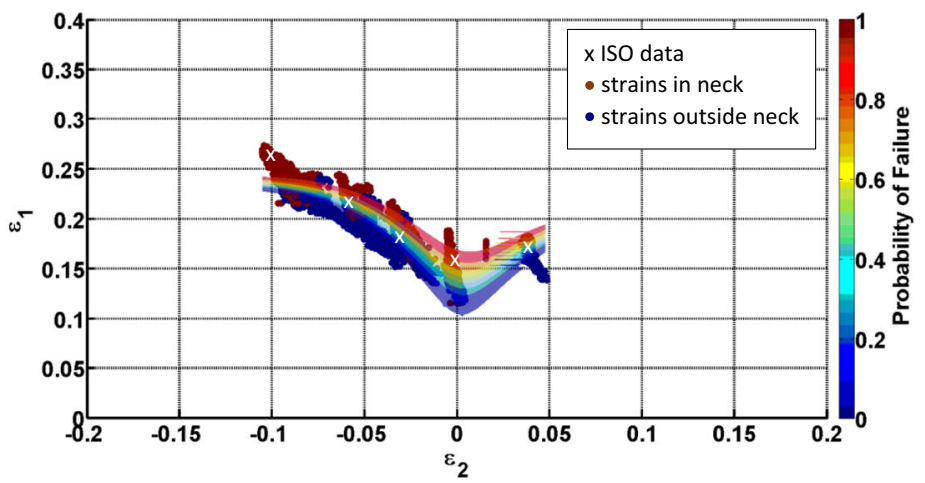

(b)

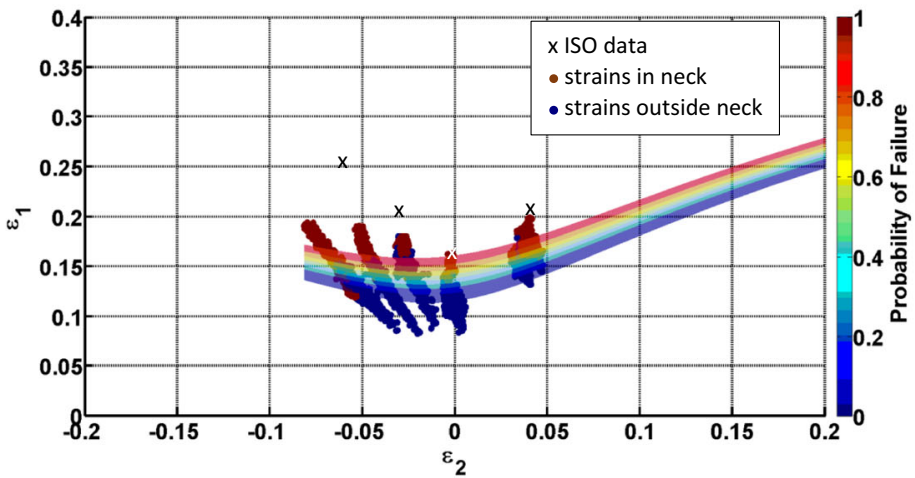

(c)

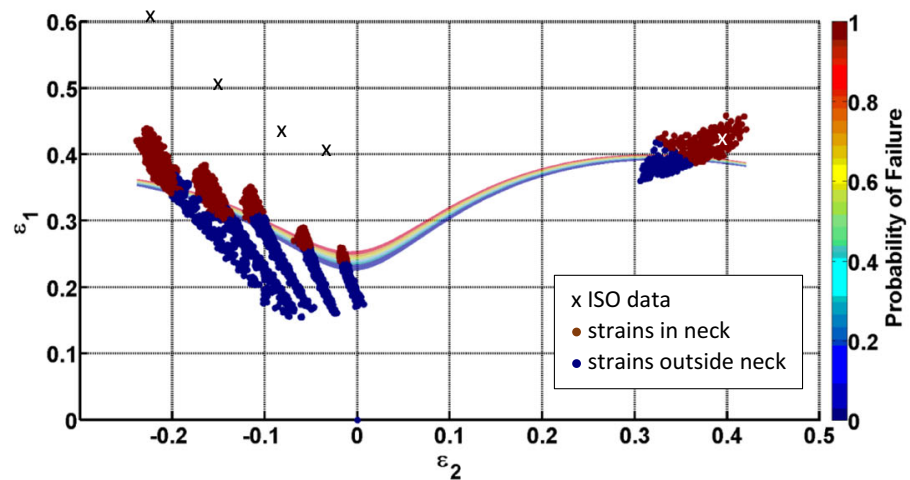

(d)

Fig. 13 a Probability map of the forming limit for AA6111T4 consisting of contours of constant probability to failure (raw data from [17]). b Probability map of the forming limit for NG5754-O consisting of contours of constant probability to failure. c Probability map of the forming limit for DP600 consisting of contours of constant probability to failure. d Probability map of the forming limit for MS3 consisting of contours of constant probability to failure 
Fig. 14 Plot of the mean difference in thickness strain of components 1 and 2 of the GMM against DIC measurement for MS3. The inflection is more gradual than AA6111-T4 (Fig. 12)

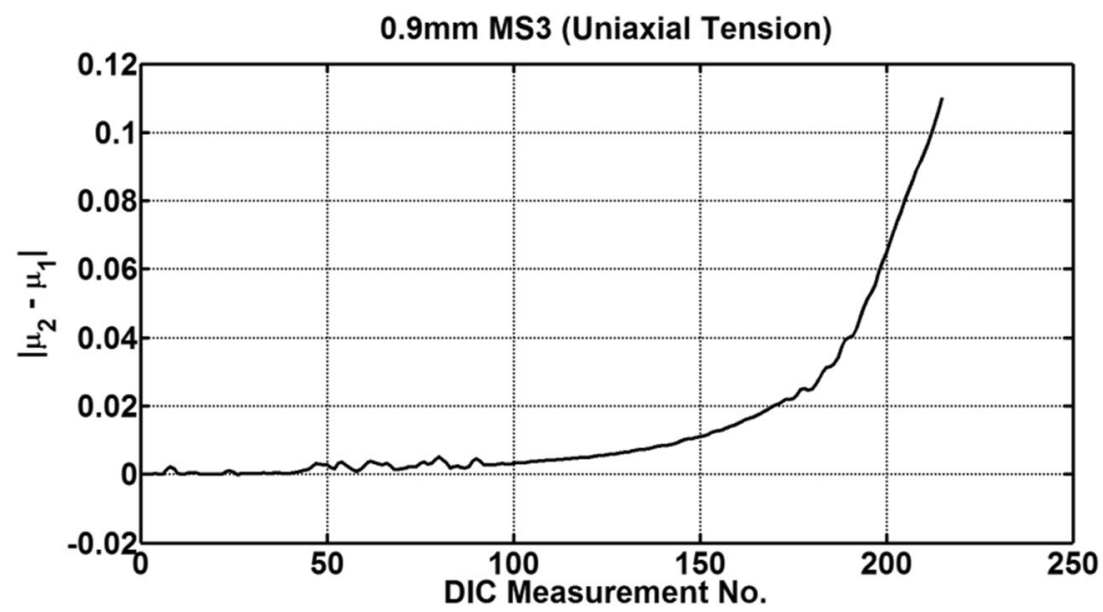

forming limits measured with the ISO technique. In contrast, the probabilistic forming limit curve is consistently lower than the ISO method and is sensitive enough to identify the onset of diffuse necking in MS3. For the AA6xxx grade aluminiums, Table 1 shows that there are no clear trends for the deformation parameters used in past time-dependent methods compared with the ISO method. In contrast, the probabilistic forming limit method measures forming limits to be lower for AA6111T4. For NG5754-O, the probabilistic forming limits are measured to be higher than the ISO method. This may be due to the presence of Luders bands in NG5754-O during deformation that results in highly heterogeneous distribution of strains on the surface of the samples. This may have affected the forming limits calculated by both the probabilistic method outlined here and the ISO method.

The characterisation of measured strains as PDFs showed that deformation during the "uniform plastic deformation" and "necking" phases is heterogeneous in all four materials. In particular, a range of strain deformation existed in the neck. When this uncertainty is incorporated into the description of forming limits, the width of the probability contours conveys the idea of the level of heterogeneity that occurs in the material. The widths were material dependent and reflected the range of strains in the neck that had $P\left(g_{2}\left(\varepsilon_{3}\right) \mid x\right)>0.5$. NG5754-O had the greatest width $(\sim 0.07$ strain $)$ in the plane strain path and MS3 had the lowest $(\sim 0.03$ strain). By accounting for the range of strains in the neck, the width of the probability band is a logical starting point for balancing the required forming windows with a risk to failure for individual grades.

There are several sources of this heterogeneity, such as the anisotropy of grains and deformation that is localised to slip systems within grains. However, the scale of this structure is of the order of $10 \mu \mathrm{m}$, which is several magnitudes smaller to the size of the size of the gauge area of the FLC sample $(30 \mathrm{~mm})$. Small [19] speculated that heterogeneity may persist at the macroscale if it is caused by surface roughness because this can come about through collective granular distortions. The resulting macroscopic-scale roughness may influence failure through variations in the sheet's effective thickness.

\section{Conclusions}

Forming limit curves are an important component for the simulation of sheet metal forming processes. However, they average out the heterogeneity in plastic deformation to define the threshold of failure in a binary or deterministic manner. In reality, it is acknowledged that the deformation and failure of materials are heterogeneous. This work shows that this heterogeneity can be detected at the macroscale using DIC and proposes a framework to account for it so that formability can be seen more appropriately as a risk to failure.

An investigation was carried out on 2 aluminium grades, NG5754-O, AA6111-T4, a mild steel grade, MS3 and a dualphase steel, DP600. DIC measurements of the plastic deformation of all 4 materials were found to be heterogeneous or "noisy" and were significant compared with measurement uncertainty of the DIC.

This behaviour was incorporated in the new framework for formability by modelling it with 2-component GMMs. At the start of plastic deformation, single-mode PDFs were apparent. As deformation proceeded, the dispersion in the strains increased until the occurrence of necking, when the single mode transitioned became bimodal. The modes with higher mean strains were associated with the necking material of the 
sample. The presence of a range of strains in the neck confirmed that formability cannot be described by a single value or a forming limit.

The statistical parameters of the 2-component GMM $\left(\left|\mu_{2}-\mu_{1}\right|\right)$ were used to identify the onset of necking. At the onset of necking, the strains measured were characterised in terms of the probability that they lay in the neck. The resulting probability distribution was represented as a logistic regression that formed a probability map of forming limits of the material. The widths of the map were material dependent and indicated the range of strains in the neck. Because the widths were characteristic to each material, they are logical starting point for balancing the requirements for part design with the risk to failure for individual materials.

\section{Appendix. Experimental data of experiments to measure uncertainty of the DIC system}

Acknowledgements The authors would like to thank Dr Alan Carr, formerly of Novelis UK Ltd. who provided the initial direction in this research. Prof Tom Nichols, formerly of the Department of Statistics, Warwick, who provided invaluable guidance on the statistical aspects of this work and the Simulation Team at WMG, past and present, who provided advice and assistance throughout this work.

Funding information The study received funding (EPSRC Grant no. GR/ T11371/01) from the Engineering and Physical Sciences Research Council, UK and Jaguar Land Rover.

Data availability The raw data for AA6111-T4 $(1.2 \mathrm{~mm})$ required to reproduce the forming map findings are available to download from http://wrap.warwick.ac.uk/115556. The structure of this data is representative of the other materials. The method for processing the data is described in the "Modelling the heterogeneity of plastic deformation" section. A video of the evolution of strains for AA6111T4 can be downloaded from http://wrap.warwick.ac.uk/115846/.

Table 3 Results for strains measured by DIC obtained in "zero strain" tests. SE of mean denotes the standard deviation

\begin{tabular}{|c|c|c|c|c|c|c|c|c|c|c|}
\hline Experiment & $\begin{array}{l}\text { Depth } \\
(\mathrm{mm})\end{array}$ & $\begin{array}{l}\text { Force } \\
(\mathrm{KN})\end{array}$ & $\begin{array}{l}\text { Orientation } \\
\left({ }^{\circ}\right)\end{array}$ & Facets & $\begin{array}{l}\mu \text { (Minor } \\
\text { Strain) }\end{array}$ & $\begin{array}{l}\mu \text { (Major } \\
\text { Strain) }\end{array}$ & $\begin{array}{l}\sigma \text { (Minor } \\
\text { Strain) }\end{array}$ & $\begin{array}{l}\sigma \text { (Major } \\
\text { Strain) }\end{array}$ & $\begin{array}{l}\text { SE of Mean } \\
\text { (Minor Strain) }\end{array}$ & $\begin{array}{l}\text { SE of Mean (Major } \\
\text { Strain) }\end{array}$ \\
\hline 1 & 0 & 0 & 0 & 3690 & $-3.81 \mathrm{E}-04$ & $3.43 \mathrm{E}-04$ & $1.00 \mathrm{E}-04$ & $4.11 \mathrm{E}-04$ & $1.34 \mathrm{E}-07$ & $5.52 \mathrm{E}-07$ \\
\hline 2 & 0 & 0 & 90 & 3542 & $-3.37 \mathrm{E}-04$ & $3.18 \mathrm{E}-04$ & $3.55 \mathrm{E}-04$ & $3.44 \mathrm{E}-04$ & 4.87E-07 & 4.72E-07 \\
\hline 3 & 0 & 0 & 180 & 3211 & $-3.65 \mathrm{E}-04$ & $3.41 \mathrm{E}-04$ & $3.68 \mathrm{E}-04$ & 4.60E-04 & $5.30 \mathrm{E}-07$ & $6.63 \mathrm{E}-07$ \\
\hline 4 & 0 & 0 & 270 & 3459 & $-3.42 \mathrm{E}-04$ & $3.63 \mathrm{E}-04$ & $3.81 \mathrm{E}-04$ & 4.07E-04 & $5.29 \mathrm{E}-07$ & $5.65 \mathrm{E}-07$ \\
\hline 5 & 0 & 300 & 0 & 3432 & -3.42 E-04 & 3.26 E-04 & 4.07 E-04 & $3.61 \mathrm{E}-04$ & $5.67 \mathrm{E}-07$ & $5.03 \mathrm{E}-07$ \\
\hline 6 & 0 & 300 & 90 & 3363 & -3.90 E-04 & 3.46 E-04 & 4.66 E-04 & $4.222 \mathrm{E}-04$ & 6.57 E-07 & 5.94 E-07 \\
\hline 7 & 0 & 300 & 180 & 3409 & -4.54 E-04 & $3.85 \mathrm{E}-04$ & 3.90 E-04 & $4.17 \mathrm{E}-04$ & $5.45 \mathrm{E}-07$ & $5.83 \mathrm{E}-07$ \\
\hline 8 & 0 & 300 & 270 & 3442 & $-3.32 \mathrm{E}-04$ & 3.34 E-04 & $3.61 \mathrm{E}-04$ & $3.58 \mathrm{E}-04$ & $5.03 \mathrm{E}-07$ & 4.98 E-07 \\
\hline 9 & 0 & 600 & 0 & 3320 & $-3.46 \mathrm{E}-04$ & $3.30 \mathrm{E}-04$ & 3.96 E-04 & 4.10 E-04 & $5.61 \mathrm{E}-07$ & $5.81 \mathrm{E}-07$ \\
\hline 10 & 0 & 600 & 90 & 3515 & $-3.61 \mathrm{E}-04$ & $3.49 \mathrm{E}-04$ & 3.72 E-04 & 3.75 E-04 & $5.12 \mathrm{E}-07$ & $5.16 \mathrm{E}-07$ \\
\hline 11 & 0 & 600 & 180 & 2952 & -3.65 E-04 & $3.20 \mathrm{E}-04$ & $4.20 \mathrm{E}-04$ & $4.39 \mathrm{E}-04$ & $6.31 \mathrm{E}-07$ & $6.60 \mathrm{E}-07$ \\
\hline 12 & 0 & 600 & 270 & 3349 & $-3.34 \mathrm{E}-04$ & 3.72 E-04 & 3.79 E-04 & $3.83-04$ & $5.35 \mathrm{E}-07$ & 5.40 E-07 \\
\hline 13 & 10 & 0 & 0 & 4230 & -3.16 E-04 & $2.602-04$ & $2.65 \mathrm{E}-04$ & 2.70 E-04 & 3.33 E-07 & 3.38 E-07 \\
\hline 14 & 10 & 0 & 90 & 4315 & -3.67 E-04 & 3.00 E-04 & 3.18 E-04 & 3.29 E-04 & 3.95 E-07 & 4.09 E-07 \\
\hline 15 & 10 & 0 & 180 & 4302 & -3.37 E-04 & $3.11 \mathrm{E}-04$ & 3.15 E-04 & 3.15 E-04 & 3.15 E-07 & 3.92 E-07 \\
\hline 16 & 10 & 0 & 270 & 4503 & $-3.61 \mathrm{E}-04$ & 2.70 E-04 & 3.18 E-04 & 2.95 E-07 & $3.87 \mathrm{E}-07$ & 3.59 E-07 \\
\hline 17 & 10 & 300 & 0 & 4243 & $-3074 \mathrm{E}-04$ & $3.21 \mathrm{E}-04$ & $3.48 \mathrm{E}-04$ & $3.43 \mathrm{E}-04$ & $4.36 \mathrm{E}-07$ & $4.30 \mathrm{E}-07$ \\
\hline 18 & 10 & 300 & 90 & 4319 & $-3.39 \mathrm{E}-04$ & $2.87 \mathrm{E}-04$ & $3.08 \mathrm{E}-04$ & $3.01 \mathrm{E}-04$ & $3.82 \mathrm{E}-07$ & 3.74 E-07 \\
\hline 19 & 10 & 300 & 180 & 4350 & -3.20 E-04 & 2.90 E-04 & $2.93 \mathrm{E}-04$ & $2.90 \mathrm{E}-04$ & $3.63 \mathrm{E}-07$ & $.59 \mathrm{E}-07$ \\
\hline 20 & 10 & 300 & 270 & 4417 & $-3.59 \mathrm{E}-04$ & 2.90 E-04 & $3.13 \mathrm{E}-04$ & $3.06 \mathrm{E}-04$ & $3.85 \mathrm{E}-07$ & $3.76 \mathrm{E}-07$ \\
\hline 21 & 10 & 600 & 0 & 4301 & -3.09 E-04 & $2.22 \mathrm{E}-04$ & 2.50 E-04 & 2.40 E-04 & 3.11 E-07 & 2.99 E-07 \\
\hline 22 & 10 & 600 & 90 & 4289 & $-3.35 \mathrm{E}-04$ & $3.21 \mathrm{E}-04$ & 3.26 E-04 & 3.35 E-04 & 4.07E-07 & 4.18 E-07 \\
\hline 23 & 10 & 600 & 180 & 4428 & $-3.46 \mathrm{E}-04$ & 2.99 E-04 & 3.14 E-04 & 3.28 E-04 & $3.85 \mathrm{E}-07$ & 4.02 E-07 \\
\hline 24 & 10 & 600 & 270 & 4496 & $-3.45 \mathrm{E}-04$ & $3.96 \mathrm{E}-04$ & $3.83 \mathrm{E}-04$ & 3.91E-04 & 4.66E-07 & $4.76 \mathrm{E}-07$ \\
\hline 25 & 20 & 0 & 0 & 4385 & $-4.13 \mathrm{E}-04$ & 4.15E-04 & 4.43E-04 & 4.34E-04 & $5.46 \mathrm{E}-07$ & $5.35 \mathrm{E}-07$ \\
\hline 26 & 20 & 0 & 90 & 4246 & $-3.81 \mathrm{E}-04$ & $3.89 \mathrm{E}-04$ & $4.16 \mathrm{E}-04$ & 4.09E-04 & $5.21 \mathrm{E}-07$ & 5.13E07 \\
\hline
\end{tabular}


Table 3 (continued)

\begin{tabular}{|c|c|c|c|c|c|c|c|c|c|c|}
\hline Experiment & $\begin{array}{l}\text { Depth } \\
(\mathrm{mm})\end{array}$ & $\begin{array}{l}\text { Force } \\
(\mathrm{KN})\end{array}$ & $\begin{array}{l}\text { Orientation } \\
\left(^{\circ}\right)\end{array}$ & Facets & $\begin{array}{l}\mu \text { (Minor } \\
\text { Strain) }\end{array}$ & $\begin{array}{l}\mu \text { (Major } \\
\text { Strain) }\end{array}$ & $\begin{array}{l}\sigma \text { (Minor } \\
\text { Strain) }\end{array}$ & $\begin{array}{l}\sigma \text { (Major } \\
\text { Strain) }\end{array}$ & $\begin{array}{l}\text { SE of Mean } \\
\text { (Minor Strain) }\end{array}$ & $\begin{array}{l}\text { SE of Mean (Major } \\
\text { Strain) }\end{array}$ \\
\hline 27 & 20 & 0 & 180 & 4357 & $-3.32 \mathrm{E}-04$ & $3.11 \mathrm{E}-04$ & $3.36 \mathrm{E}-04$ & $3.14 \mathrm{E}-04$ & $4.15 \mathrm{E}-07$ & $3.88-07$ \\
\hline 28 & 20 & 0 & 270 & 4206 & $-3.80 \mathrm{E}-04$ & $3.47 \mathrm{E}-04$ & $3.80 \mathrm{E}-04$ & $3.72 \mathrm{E}-04$ & 4.79E-07 & $4.69-07$ \\
\hline 29 & 20 & 300 & 0 & 4423 & $-3.57 \mathrm{E}-04$ & $3.62 \mathrm{E}-04$ & $3.83 \mathrm{E}-04$ & $4.57 \mathrm{E}-04$ & 4.70E-07 & $4.38 \mathrm{E}-07$ \\
\hline 30 & 20 & 300 & 90 & 4362 & $-4.55 \mathrm{E}-04$ & $4.08 \mathrm{E}-04$ & 4.69E-04 & $4.28 \mathrm{E}-04$ & 5.79E-07 & $5.30 \mathrm{E}-07$ \\
\hline 31 & 20 & 300 & 180 & 4365 & $-4.23 \mathrm{E}-04$ & $4.12 \mathrm{E}-04$ & 4.43E-04 & $4.32 \mathrm{E}-04$ & 5.47E-07 & 5.33E-07 \\
\hline 32 & 20 & 300 & 270 & 4356 & $-3.94 \mathrm{E}-04$ & 3.82E-04 & 3.99E-04 & $3.95 \mathrm{E}-04$ & 4.94E-07 & $4.88 \mathrm{E}-07$ \\
\hline 33 & 20 & 600 & 0 & 4352 & $-3.68 \mathrm{E}-04$ & $3.74 \mathrm{E}-04$ & $3.82 \mathrm{E}-04$ & $3.79 \mathrm{E}-04$ & 4.72E-07 & 4.70E-07 \\
\hline 34 & 20 & 600 & 90 & 4290 & $-3.22 \mathrm{E}-04$ & $3.66 \mathrm{E}-04$ & $3.48 \mathrm{E}-04$ & $3.60 \mathrm{E}-04$ & $4.33-07$ & 4.49E-07 \\
\hline 35 & 20 & 600 & 180 & 4286 & -3.90E.04 & 4.19E-04 & 4.14E-04 & 4.49E-04 & $5.6 \mathrm{E}-07$ & $5.60 \mathrm{E}-07$ \\
\hline 36 & 20 & 600 & 270 & 4398 & $-4.06 \mathrm{E}-04$ & $3.66 \mathrm{E}-04$ & 4.23E-04 & $3.85 \mathrm{E}-04$ & $5.21 \mathrm{E}-07$ & 4.74E-07 \\
\hline 37 & 30 & 0 & 90 & 4350 & $-3.75 \mathrm{E}-04$ & $3.44 \mathrm{E}-04$ & $3.62 \mathrm{E}-04$ & $3.46 \mathrm{E}-04$ & 4.49E-07 & $4.30 \mathrm{E}-07$ \\
\hline 38 & 30 & 0 & 90 & 4350 & $-3.75 \mathrm{E}-04$ & $3.60 \mathrm{E}-04$ & $3.68 \mathrm{E}-04$ & $5.59 \mathrm{E}-04$ & 4.56E-07 & $6.93 \mathrm{E}-07$ \\
\hline 39 & 30 & 0 & 180 & 4327 & $-4.91 \mathrm{E}-04$ & 4.95E-04 & 5.19E-04 & 4.91E-04 & $6.44 \mathrm{E}-07$ & $6.10 \mathrm{E}-07$ \\
\hline 40 & 30 & 0 & 270 & 4345 & $-3.92 \mathrm{E}-04$ & $4.18 \mathrm{E}-04$ & $3.89 \mathrm{E}-04$ & 4.21E-04 & $4.81 \mathrm{E}-07$ & $5.21 \mathrm{E}-07$ \\
\hline 41 & 30 & 300 & 0 & 4385 & $-4.10 \mathrm{E}-04$ & $3.85 \mathrm{E}-04$ & 4.10E-04 & $3.93 \mathrm{E}-04$ & 5.05E-07 & $4.85 \mathrm{E}-07$ \\
\hline 42 & 30 & 300 & 90 & 4372 & $-4.01 \mathrm{E}-04$ & 4.02E-04 & 4.03E-04 & 4.15E-04 & 4.92E-07 & 4.76E-07 \\
\hline 43 & 30 & 300 & 270 & 4341 & $-3.98 \mathrm{E}-04$ & $3.90 \mathrm{E}-04$ & $3.99 \mathrm{E}-04$ & $3.87 \mathrm{E}-04$ & 4.92E-07 & $4.76 \mathrm{E}-07$ \\
\hline 44 & 30 & 300 & 270 & 4341 & $-4.84 \mathrm{E}-04$ & 4.73E-04 & 4.95E-04 & 4.79E-04 & $6.14 \mathrm{E}-07$ & 5.94E-07 \\
\hline 45 & 30 & 600 & 0 & 4394 & $-3.98 \mathrm{E}-04$ & $3.90 \mathrm{E}-04$ & $3.92 \mathrm{E}-04$ & $3.98 \mathrm{E}-04$ & 4.83E-07 & 4.90E-07 \\
\hline 46 & 30 & 600 & 90 & 4323 & $-4.23 \mathrm{E}-04$ & $4.26 \mathrm{E}-04$ & $4.36 \mathrm{E}-04$ & $4.22 \mathrm{E}-04$ & 5.41E-07 & $5.24 \mathrm{E}-07$ \\
\hline 47 & 30 & 600 & 180 & 4367 & $-4.76 \mathrm{E}-04$ & $5.21 \mathrm{E}-04$ & 4.99E-04 & $5.18 \mathrm{E}-04$ & $6.16 \mathrm{E}-07$ & $6.41 \mathrm{E}-07$ \\
\hline 48 & 30 & 600 & 270 & 4367 & 5019E-04 & 5019E-04 & 4.97E-04 & $5.17 \mathrm{E}-04$ & $6.14 \mathrm{E}-07$ & 6.39E-07 \\
\hline
\end{tabular}

Open Access This article is licensed under a Creative Commons Attribution 4.0 International License, which permits use, sharing, adaptation, distribution and reproduction in any medium or format, as long as you give appropriate credit to the original author(s) and the source, provide a link to the Creative Commons licence, and indicate if changes were made. The images or other third party material in this article are included in the article's Creative Commons licence, unless indicated otherwise in a credit line to the material. If material is not included in the article's Creative Commons licence and your intended use is not permitted by statutory regulation or exceeds the permitted use, you will need to obtain permission directly from the copyright holder. To view a copy of this licence, visit http://creativecommons.org/licenses/by/4.0/.

\section{References}

1. Hosford, W.F. \& Caddell, R.M. (2011) Metal forming: mechanics and metallurgy 4th ed., Cambridge University Press

2. ISO 12004-2:2008 (2008) Metallic materials: Part 2: Determination of forming limit curves in the laboratory

3. Merklein M, Kuppert A, Geiger M (2010) Time dependent determination of forming limit diagrams. CIRP Ann 59:295-298. https:// doi.org/10.1016/j.cirp.2010.03.001

4. Volk W, Hora P (2010) New algorithm for a robust userindependent evaluation of beginning instability for the experimental FLC determination. Int J Mater Form 4:339-346. https://doi.org/10.1007/s12289-010-1012-9

5. Hotz W, Merklein M, Kuppert A, Friebe H, Klein M (2013) Time dependent flc determination comparison of different algorithms to detect the onset of unstable necking before fracture. Key Eng Mater 549:397-404. https://doi.org/10.4028/www.scientific.net/KEM. 549.397

6. Min J, Stoughton TB, Carsley JE, Lin J (2017) Comparison of DIC methods of determining forming limit strains. Procedia Manuf 7 : 668-674. https://doi.org/10.1016/j.promfg.2016.12.099

7. Huang G, Sriram S, Yan B (2008) Digital image correlation technique and its application in forming limit curve determination. Int. Deep Draw. Res. Gr.:153-162

8. Vysochinskiy D, Coudert T, Hopperstad OS, Lademo OG, Reyes A (2016) Experimental detection of forming limit strains on samples with multiple local necks. J Mater Process Technol 227:216-226. https://doi.org/10.1016/j.jmatprotec.2015.08.019

9. Martínez-Donaire AJ, García-Lomas FJ, Vallellano C (2014) New approaches to detect the onset of localised necking in sheets under through-thickness strain gradients. Mater Des 57:135-145. https:// doi.org/10.1016/j.matdes.2014.01.012

10. Boas W, Hargreaves ME (1948) On the inhomogeneity of plastic deformation in the crystals of an aggregate. Proc R Soc Lond A Math Phys Sci 193:89-97

11. Hazra S, Efthymiadis P, Proprentner D, Shollock B, Dashwood R (2017) The strain fields present during the bending of ultra-high strength steels. Procedia Eng 207:1314-1319 
12. Tadros AK, Mellor P (1978) An experimental study of in-plane stretching of sheet metal. Int J Mech Sci 20:121-134

13. van Minh H, Sowerby R, Duncan JL (1974) Variability of forming limit curves. Int J Mech Sci 16:31-44

14. Janssens K, Lambert F, Vanrostenberghe S, Vermeulen M (2001) Statistical evaluation of the uncertainty of experimentally characterised forming limits of sheet steel. J of Mater Process Technol 112:174-184

15. Hild F, Roux S (2006) Digital image correlation: from displacement measurement to identification of elastic properties-a review. Strain 42:69-80, Digital Image Correlation: from Displacement Measurement to Identification of Elastic Properties - a Review

16. Small N (2019) Thickness strain evolution in a Marciniak test. http://wrap.warwick.ac.uk/115846/
17. Small N (2019) Digital image correlation of Marciniak tests for AA6111-T4 (1.2 mm). http://wrap.warwick.ac.uk/115556

18. Strano M, Colosimo BM (2006) Logistic regression analysis for experimental determination of forming limit diagrams. Int J Mach Tools Manuf 46:673-682. https://doi.org/10.1016/j.ijmachtools. 2005.07.005

19. Small N (2015) A statistical method for determining and representing formability. University of Warwick

Publisher's note Springer Nature remains neutral with regard to jurisdictional claims in published maps and institutional affiliations. 